\title{
Discussion: Segmentation algorithms for road marking digital image analysis
}

\author{
M. P. N. Burrow, H. T. Evdorides and M. S. Snaith
}

S. Xavier, Highways Agency, Traffic Signs Team, Dorking Office, UK

1. Congratulations to the authors! This is a very useful exercise as it uses the mathematical technique of algorithms to study the body of road markings against the contrast of bituminous road surface. It is able to identify to what extent the material present is worn out. This is very useful for high speed inspection purposes as a walk about inspection with the involvement of traffic management is not only resource intensive but also disrupts traffic flow and causes delay to road users.

2. Practising civil engineers approach this aspect of the inspection of road markings in a different way as set out in BS 3262 which is now superseded by BS EN 1824. ${ }^{1,2}$ The former used a wire grid to place over the road marking. In that method a panel of inspectors formed a view of how much of the road marking remained within each grid square in a formal road trial and summed it over the test area and applied a simple calculation to determine the wear index. In the BS EN 1824 there is a 'faster' method that permits a coloured photograph to be taken on site and analysed back in the office. Instead of this somewhat cumbersome operation, an alternative permitted in the BS EN 1824 is to measure the property known as minimum luminance coefficient in diffuse illumination $\left(Q_{d}\right)$ using a portable instrument. This does not, however, tell us anything about how much of the line is worn out but nevertheless measures reflection under daylight or street lighting. This helps to form a view about threshold values for pre-view time of the road users. Incidentally, there is a useful European report and software for this which unfortunately does not take into consideration the presence of road studs. ${ }^{3}$ I believe the BS ENs are reliable as there are years of tried and tested engineering methods behind them but they are costly and disruptive to traffic as the authors themselves have found.

3. In this context, the authors proposal is very attractive if photographic or video images can be taken from a high speed monitor and they are speedily analysed for useful results for decision making to replace a badly eroded line. Some pioneering work in this area was carried out at TRL between 1992 and 1995. Both Mr B. W. Ferne and I refer to it in our earlier discussion contribution. ${ }^{4}$ Moving on from there, there are two monitors used by industry for a different measurement at high speed. They are known as the Ecodyn and Laserlux. Both measure the property of retroreflection $\left(R_{L}\right)$ which is important for visibility at night. The latter system also has an option to take video images and a GPS facility.

4. Having taken snap shots at high speed, which may be considered as equivalent to taking walk about inspection photographs to BS EN 1824, the next step is analyse them in minute form for engineering decision making processes.

5. The authors have taken the trouble to study seven photographs. Simple visual inspection is described but I wonder what would be the corresponding assessment using the BS 3262 grid method and BS EN 1824 method albeit the photographs may be in black and white. It may be $Q_{d}$ measurements were not taken on site at that time or samples may not have been taken for closer examination in the laboratory.

6. The Highways Agency maintenance standard TD 26 prepublication draft $^{5}$ gives guidance on measurement on wear index or $Q_{d}$ by inspectors under traffic management conditions permitting. The use of high speed monitors for the measurement of $R_{L}$ is also permitted subject to correlation with static measurement instruments.

7. Perhaps the authors could comment on whether the algorithmic methodology could be easily devised to form a view of how much of the road markings were remaining per square metre in each of the seven photographs and if so what the results are and how they compare with BS 3262 and BS EN 1824 methods. Do they have a view on how long they need to develop their methodology before road making industry partners who are already operating Edcodyn ${ }^{6}$ and Laserlux ${ }^{7}$ may begin to consider them as useful bolt-on devices to their systems?

\section{REFERENCES}

1. BS EN 3262-2: Hot-applied thermoplastic road marking materials - Specification for road performance. British Standards Institution, London, 1999.

2. BS EN 1824: Road marking materials - Road trials. British Standards Institution, London, 1999.

3. European Commission 1999, Directorate General Transport, Co-operation in the Field of Scientific and Technical Research, COST 331 - Requirements for Horizontal Road Markings - Final Report of the Action. 
4. Proc. Instn Civ. Engrs Transport, May 2002, 153, Issue 2, 144-146.

5. TD 26: Inspection and maintenance of road markings and road studs on motorways and all-purpose trunk roads. Pre-publication draft (Available from Sydney.Xavier@ highways.gsi.gov.uk).

\section{Web sites:}

6. Prismo's Ecodyn system, www.prismo.co.uk/ ecodyn_text.htm.

7. Gamma Scientific's Laserlux system, www.gamma-sci.com.

\section{Authors' reply}

We would like to thank Mr Xavier for his useful contribution to the discussion of the measurement of road marking performance using image analysis techniques.

Mr Xavier raises a number of important issues regarding the measurement of road marking wear, or erosion. The methodology presented in the paper ${ }^{1}$ and in an earlier paper ${ }^{2}$ seek to measure the wear exactly. That is to determine the amount of road marking present on a road surface compared to its ideal uneroded size (i.e. the area specified by the standards prior to its laying). The methodology was successfully tested on a great many images of the road surface, the seven images presented in the paper ${ }^{1}$ were selected as they were considered to be representative of the various types of road markings which may be encountered. The process described in the standards ${ }^{3,4}$ is, as Mr Xavier comments, a practical method suitable for engineers in the field. The resulting measure, the Wear Index, is an approximate measure of wear which may not be accurate. ${ }^{5,6}$ Should it be considered necessary in any future development of the system presented ${ }^{1,2}$ the algorithms used to determine wear may be very easily adjusted to measure the Wear Index.

Mr Xavier asks whether the algorithmic methodology could easily be devised to determine the area of road marking remaining in each of the seven images presented in the paper. ${ }^{1}$ This measure is very similar to measuring the erosion of the road marking and as the methodology devised is very flexible such arithmetic problems may be easily computed by the system. For images 1, 2, 4, 5 and 6 the percentages of road marking remaining are $99 \%, 96 \%, 20 \%, 67 \%$ and $71 \%$ respectively $\left(\mathrm{cf}^{2}{ }^{2}\right)$. As image 3 is not of a road line and the dimensions of the image are unknown it is impossible to determine the area of road marking remaining. Image 7 does not contain a road marking and is identified as such by the methodology $\left(\right.$ see $\left.^{2}\right)$.

Concerning the measurement of the luminance coefficient in diffuse illumination $\left(Q_{d}\right)$, we have carried out a great deal of, as yet unpublished, research on how it may be determined from images of the road surface. ${ }^{6}$ The results, which are promising, also show some additional research is still required particularly with regard to the device used to capture the images. The measurement of $Q_{d}$ in the standards, also ${ }^{3,4,7}$ requires very specific lighting conditions and angles of measurement, these the research ${ }^{6}$ has found affect the value of $Q_{d}$ measured and their replication in the field may not be straightforward.

Finally, Mr Xavier enquires about the suitability of the methodology presented ${ }^{1,2}$ for an immediate industrial application. In the Highways research group we are always interested in seeing the products of our work being exploited and we believe this particular piece of work is very suitable as Mr Xavier suggests for an almost immediate practical application given an appropriate image capturing system. Indeed, we would welcome an approach by the industry partners mentioned by Mr Xavier. However, as with previous work in this area with the measurement of cracking from images of the roads surface, whilst the Group has not directly benefited from the spin-offs from that work it is nonetheless gratifying to see the concepts developed at Birmingham in the late 1980s and early 1990s, ${ }^{8,9,10}$ with the initial assistance of the US Corps of Engineers, being at the core of a large number of the digital crack assessment systems currently under development.

\section{Frambourg, Light Tec, Hyeres, France}

Please find below a few comments. I am not a road engineer, but rather a mathematician.

Unfortunately, some information is missing, such as the experimental set-up, but I assumed the study was made in a static environment, with the camera looking vertically down to the markings.

What was the resolution of the image and the acquisition time? Was the camera colour or black and white? I think this was a black and white camera, $512 \times 512,8$ bits, but my question is: what similarity of results can we expect with a colour camera, averaging the three colour images (RGB)?

\section{A few other details need amplifying.}

For instance, when I can read peaks at 0 or 255 grey level, it means to me that the exposure time for the image may not be adapted. Did the authors keep the same exposure time for every image (as would be the case for an automated measurement)?

In Fig. 4 there is a mention of three peaks. This often happens in the UK when the white line, is surrounded by a black region for better contrast. How did the computation work in this case? We have to check whether the threshold is the white line's threshold and not the black area.

My final regret is that I felt a lack of conclusions. It is said that the sub-image thresholding works fine, which we could expect from the algorithm. But can we deduce that the others are not suitable? If this technique is adopted for mobile measurements, then would speed change the results?

Please do not take these remarks as criticisms; they are rather a request for more information. I would not have written so much if I had not found the study so interesting. And definitely it seems that image processing may help on daylight roadmarking verification.

\section{Authors' reply}

The subject of the paper focused on the selection of suitable algorithms for the important image analysis process of identifying road markings from digital images and separating these images from the background. A more general description of the research project is dealt with in an earlier paper. ${ }^{11}$ 
The cameras were looking vertically down, but many of the images used in the research were not taken in a static environment but were supplied by the Transport Research Laboratory (TRL). These monochrome images were obtained under conditions suitable for the measurement of pavement distress data (see for example images 4-7 in the paper on segmentation algorithms). The algorithms were also tested on a number of the images obtained from colour video images of the road surface (for example images 1-3 in the paper). The camera used to capture these images was pointed vertically down, but was a colour video camera.

Typically 1 pixel represented $2 \mathrm{~mm}$ of road surface in the images.

The acquisition times of the images supplied by the TRL are unknown, but the exposure time was calibrated to collected pavement distress data (e.g. cracks and potholes).

Some of the images were taken with a colour camera and some with a monochrome (black and white) camera as mentioned above. In the case of colour images, standard transformations were used to transform RGB values to luminance (and X, Y, Z tristimulus) values.

As you are no doubt aware, the exposure time for video images taken from solid-state cameras is dependent on the chargecoupled devices (CCD) used, and on the electronic shuttering that occurs when an image is scanned. As the images were captured with different cameras, the exposure time was not the same for all the images. Those for images 1-3 were the same, as were those for images 4 and 5 .

However, the exposure time is not important for the analysis of erosion, and will not affect the way the algorithms described in the paper function. Nevertheless, for the measurement of the other performance characteristics of road markings (see earlier paper ${ }^{11}$ ) it is important to ensure that the video camera used is suitable. In practice this means that, in addition to the exposure time, the following factors need to be considered: the response of a camera to illumination levels; the response and homogeneity of individual sensors (CCDs) to illumination; the sensitivity level and dynamic range of the camera; automatic adjustments made by the camera, including automatic gain control and auto-iris control; and the shuttering mechanism in use.

Regarding Fig. 4, contrast this with Fig. 6, where the contrast of the road marking with the background is poor and there is no such black region.

For the optimal technique selected (sub-image thresholding), the image is segmented by determining thresholds for small areas of the image using Kittler and Illingworth's J function as described in Section 4 of the paper. This section of the paper also describes the techniques used to identify (and consequently ignore) cases where valid thresholds are determined for sub-images containing only dark areas (e.g. black) on a background road surface. It is evident from the results presented (see particularly Figs 4-6) that the process of sub-image thresholding segments such images very well.

On your request for conclusions, as described in Section 6 of the paper, from the variety of images analysed using the techniques presented in our work it is our opinion that subimage thresholding is the optimal technique for segmenting all the types of road marking image investigated.

Regarding the effects of speed, the techniques were developed for the analysis of video images of the road surface taken from a moving vehicle, so they are designed to be suitable for mobile measurements, and as long as the image capture system is appropriate then speed should not affect the results.

The Highway Research Group at the University of Birmingham has over 10 years of research expertise in this area, starting with the digital image analysis of pavement crack data and progressing through to road markings. We would be very happy for you to come and meet us and see our work should you so wish, and we welcome your comments very much. Thank you for your interest.

\section{REFERENCES}

1. Burrow, M. P. N., Evdorides, H. T. and Snaith, M. S. Segmentation algorithms for digital image analyis. Proc. Instn Civ. Engrs Transport, 2003, 156, 17-28.

2. Burrow, M. P. N., Evdorides, H. T. and SNAITH, M. S. Road marking assessment using digital image analysis. Proc. Instn Civ. Engrs Transport, 2000, 141, 107-112.

3. BS EN 3262: Part 2. Hot-applied thermoplastic road marking materials - specification for road performance. British Standards Institution, London, 1999.

4. BS EN 1824: Road marking materials - Road trials. British Standards Institution, London, 1998.

5. MundY, M. J. and RichARDS, D. M. Measurement of road marking paint wear using digital image analysis. Proceedings, 16th ARRB Conference, Perth, Australia, 1992, 16, Part 4, 361-76.

6. BURROW, M. P. N. The development of an automated system for the analysis of road markings. $\mathrm{PhD}$ thesis, School of Civil Engineering, The University of Birmingham, UK, 1998.

7. BS EN 1436: Road marking materials - Road marking performance for road users. British Standards Institution, London. 1998.

8. Deakin, T. H. G., Snaith, M. S., Kosasih, D. and Finch, R. The assessment of rutting and cracking of road pavements by cheap and rapid means Proceedings of the Sixth International Road Federation African Highway Conference, Cairo, 1986, pp. 67-76.

9. KoSASIH, D. and Snaith, M. S. Automated crack data collection and analysis. Proceedings of the Sixth Conference of the Road Engineering Association of Asia and Australasia, Kuala Lumpur, Vol 1, 1990.

10. Tillotson, H. T., Snaith, M. S. and Huang, Y. Image processing for road condition surveys. Proceedings of the International Conference on Advanced Technologies in Transportation and Traffic Management, Singapore, 1994, pp. 439-446.

11. Burrow M. P. N., Evdorides H. T. and SNAITH M. S. Road marking assessment using digital image analysis. Proceedings of the Institution of Civil EngineersTransportation, 2000, 141, 107-112. 